\title{
Investigating Factors Affecting Environmental Behavior of Urban Residents: A Case Study in Tehran City- Iran
}

\author{
${ }^{1}$ Khalil Kalantari, ${ }^{2}$ Hossein Shabanali Fami, ${ }^{3}$ Ali Asadi and ${ }^{4} \mathrm{H}$. Movahed Mohammadi \\ Faculty of Agricultural Economics and Development, Agricultural and Natural Resources Campus \\ University of Tehran, Karaj - Iran
}

\begin{abstract}
Environmental problems such as air and water pollution, urban garbage and climate changes in urban areas are the results of human behavior. Only change in human behavior can reduce these environmental problems. Thus studying attitude and behavior of people is a precondition to change this situation. So the main objective of this study was to find out individual and social factors affecting environmental behavior of urban citizens. To achieve this objective a conceptual framework derived out from review of literature to examine relationships among personal factors, attitude towards environment and environmental behavior. To examine this conceptual model, 1200 individuals of Tehran residents were randomly chosen and interviewed about their environmental behaviors, opinions, knowledge and sources of information on environment. The data were analyzed using correlation analysis, student's t test, analysis of variance (ANOVA) and path analysis by SPSS software. It is emerged from the present study that education and improving problem-based knowledge of Tehran residents can change their environmental attitude and increase their feeling of stress towards environment. These changes in turn improve their preparedness to act friendly with the environment, particularly with the help of environmental legislation. Results of the study showed that environmental behavior of people in urban areas directly and indirectly are under the influence of variables like age, gender, income, education, problem-based knowledge, environmental legislation, environmental attitude, feeling of stress and preparedness to act of the residents. All these together can influence and change people's behavior to preserve urban environment.
\end{abstract}

Key words: Attitude towards environment, environmental behavior, urban environment, environmental problems

\section{INTRODUCTION}

Environmental problems and the accelerating changes in living conditions have become a fundamental part of the world in general and metropolises in particular. Earlier, environmental problems have been considered as technical and economic problems; while in the recent decades the social dimensions of environmental problems such as public attention and people's attitudes towards environment have became one of the areas of environmental sociology and environmental psychology. In this respect, public environmental attitudes and ecological behavior and their environmental consequences have been investigated in developing and developed countries during the last few decades. These issues are also increasingly taking more attention of policy into account in Iran in the recent decades. Particularly, increasing population density in Tehran is putting pressure on the city's environment. Specifically, air pollution constitutes to the most serious environmental problems and threatening public health. Therefore, investigating environmental behavior of Tehran residents is a major concern of this paper. There is hardly any empirical study of environmental behavior in Iran. Thus this study was the first attempt in this respect.

The main objective of this study was to investigate factors affecting attitudes and behavior of Tehran's residents towards environment. On the basis of this main goal, the following specific objectives were investigated:

1. To find out some individual and social factors affecting environmental behavior.

2. To identify relationships among personal factors, environmental attitudes and environmental behavior.

Conceptual framework: Environmental attitudes are recognized as an indicator and component of environmental behavior. There are many theoretical and empirical approaches to investigate attitude towards environment in the respected literatures. Most of the studies related to this issue have been conducted since 1970 onwards when conceptualization of environmental attitudes as a scientific research concept gained closer attention by researchers ${ }^{[1]}$. Dimensionality was one of the most critical factors of environmental attitude studies. Initial researches looked at environmental attitudes as a uni-dimensional concept. Later, many studies explored the multi-dimensionality of 
environmental attitudes. Albrecht et al. ${ }^{[2]}$ used factor analysis and found three dimensions; "balance of nature" "limits to growth" and "man over nature". Cluck et al. ${ }^{[3]}$ took United States nation-wide data and conceptualized environmental attitudes as a three dimensional concept, including "environmental worldview", "environmental concern" and "environmental commitment". Environmental worldview represents basic and general form of environmentalism of the respondents. This form of environmentalism indicates respondents' general perceptions about the environment, relationships between the environment, economic growth and industrialization and effects of sciences and technology on the environment. Environmental concern represents values of respondents about the relationship between the environment and society and relationship between individual and the environment and perceptions of respondents about specific environmental problems. Environmental commitment represents values of respondents about commitment issues for better environmental quality. The environmental commitment issues might have willingness to pay higher taxes or costs for better environmental protection and be willing to reduce living standards to achieve a higher environmental quality.

Thus literatures available on the issue indicate that most approaches identify environmental attitude and behavior as multi-dimensional phenomena ${ }^{[4]}$. These studies reveal some factors that are consistently related to environmental behavior over time and across studies. According to Buttel and Taylor ${ }^{[[5]]}$ the strongest and most consistent predictor of environmental behavior is age. The relationship between gender and environmental concern also has been more carefully theorized than other structural variations in environmental concern ${ }^{[6]}$. Women are generally more concerned than men and the literature explores several possible mediating factors. One is gender differences in the experience and effects of parenthood. For men, parenthood leads to less environmental concern while, for women to greater concern ${ }^{[7]}$. Some other scholars such as Tarrant and Cordel ${ }^{[8]}$, Stern et al. ${ }^{[7]}$ and Arcury ${ }^{[9]}$ also discussed gender effects of environmental attitudes. Their findings have been contradictory to each other. Arcury ${ }^{[9]}$ found that female respondents were less environmentally concerned than male respondents and Tarrant and Corde ${ }^{[8]}$ and Stern et $a l .{ }^{[7]}$ reported that female had higher levels of environmentalism than male. Overall findings have indicated no clear gender difference on environmental attitudes. Because different researchers used different samples each research arrived to different result. Some studies also suggest a weak positive relationship with some measures of religious participation ${ }^{[10]}$. Antecedent factors such as social structural variables have been associated with value orientation, attitudes and environmental behaviors. Out of social structural variables, women, people with higher levels of education, younger individuals and those with a liberal political orientation support the principles of sustainable resource management ${ }^{[11]}$. A separate literature links indicators of environmentalism to sociopsychological factors including attitudes, believes, values and worldviews, identifying a wide range of correlates $^{[1]}$. Education, political ideology and place of residence also are consistently related to environmental concern $^{[9]}$. Links to other social structural variables, such as social class and occupation are weak, seldom statistically significant and show no consistent pattern across studies.

Several studies have shown that a cognitive hierarchical framework consisting of basic values, general believes, specific attitudes and behavior provide a suitable basis for understanding environmentalism. General believes in turn, influence specific attitudes and actions or behaviors ${ }^{[10,12]}$. Although the effect of knowledge is not conclusive, there have been several studies suggesting that knowledge plays an important role in enhancing the environmental attitude and behavior relationship by providing individuals with the ability to better formulate alternative views and present arguments to support their believes and behaviors ${ }^{[11]}$.

On the basis of available empirical studies and several major theories and models on environmental attitude and behavior, coherent model in respect to environmental attitudes and behavior in urban areas was developed. The attitudinal model, presented in Fig. 1, is developed as a causal representation based on the multi-component paradigm for attitudes. This leads to a view of environmental behavior in terms of a framework of cause and effect that is dependent of the attitudinal components and on selected variables derived from the social status and background of the individuals. The model forms the basis of this study and the environmental behavior. The components of environmental behavior include "environmental attitudes", behavioral tendencies to act or "preparedness to act", the cognitive components including attitudinal elements derived from "problem-based knowledge" and the emotional component of "feeling of stress". The "environmental legislation" is also an important factor, which can affect environmental behavior. Conceptualization and investigation of environmental behavior on the basis of various individual and psychological factors also provides an important contribution to our understanding of environmental attitudes and behavior in metropolis of Tehran. The literature indicated that age, education, gender, occupation, place of residence and income is the most explanatory variables related to environmental attitudes $^{[13-17]}$. All reviewed literature indicated that education is a key variable on environmental attitudes. An understanding of modern environmental issues requires high level of environmental knowledge and 


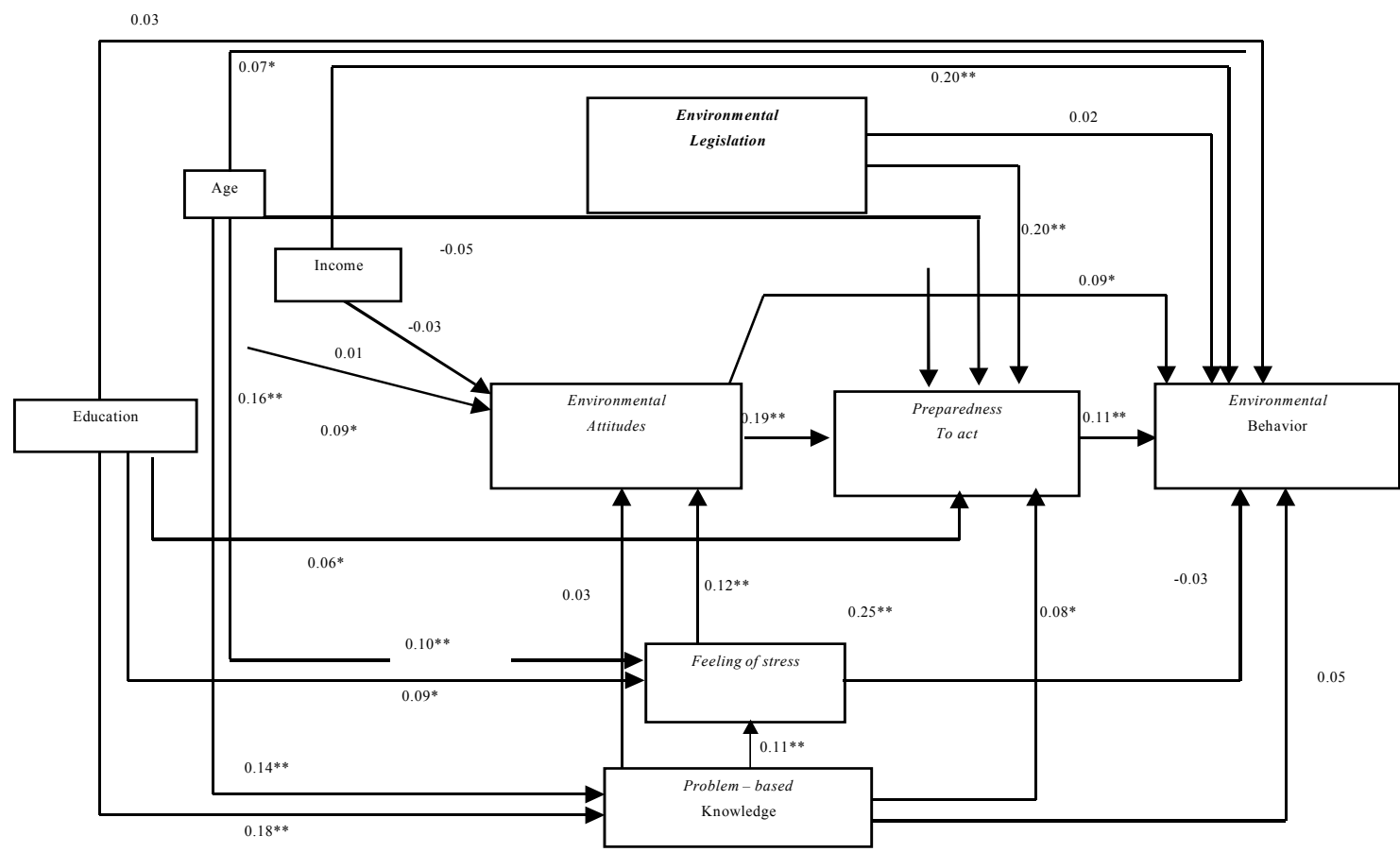

Fig. 1: The path coefficients are linear and standardized. The significance is: $* 0.05 \geq p>0.01$ and $* * 0.01 \geq p>$ 0.001. Data source: Responses from 1200 Tehran residents

likelihood of high environmental knowledge is correlated to high level of education ${ }^{[9]}$. To examine relationship between individual characteristics, environmental attitude components and environmental behavior, a conceptual framework (Fig. 1) was derived from reviewed literature and the questionnaire was developed on the basis of this model.

Hypothesis: The main hypotheses derived from the conceptual framework are:

1. Age, income, occupation, education level and environmental knowledge have a significant impact on the environmental attitude and behavior.

2. There is a significant difference between behavior of male and female with respect to environmental attitude. This is true in the case of education, occupation, income level and place of residence.

3. The people's attitudes towards environment, their feeling of stress, their preparedness to act and environmental legislation have a significant impact on environmental behavior of urban residents.

\section{MATERIALS AND METHODS}

The present study was based on a field survey. The research population of the study was all the Tehran's residents aging over 16 years old. To derive a representative sample, the research population was divided into three strata units according to the place of
Table 1: Reliability analysis (Alpha)

\begin{tabular}{lcl}
\hline Scale Name & $\begin{array}{l}\text { No. of items } \\
\text { in the scale }\end{array}$ & $\begin{array}{l}\text { Alpha } \\
\text { Value }\end{array}$ \\
\hline Environmental attitude & 10 & 0.6335 \\
Preparedness to act & 6 & 0.6931 \\
Environmental legislation & 4 & 0.6720 \\
Feeling of stress & 7 & 0.8067 \\
Environmental behavior & 11 & 0.6097 \\
\hline
\end{tabular}

residence Viz; North, South and central part of Tehran. Then, based on gender (Male \& Female) proportionate samples were drawn from each strata unit. In total, 1200 questionnaires including 400 from the north, 400 from the center and 400 from the south of Tehran were completed. In total 1403 persons were stopped for the interview but only 1200 persons were interviewed. Thus the non-response rate was $17 \%$.

A questionnaire was used for data collection and the survey worked out through face-to-face interview at local parks. To examine the reliability of the questionnaire a pilot study was conducted on 40 residents in Tehran and Coronbach's Alpha for the items of Likert type scales were calculated. The results show that an appropriate internal consistency was among the items of each scale (Table 1).

Apart from descriptive methods, several inferential techniques such as coefficient of correlation, student's $t$ test, analysis of variance (ANOVA), Duncan test and path analysis were used to analyze the data. The calculations were carried out using the "Statistical Package for the Social Sciences" (SPSS11). 
Am. J. Environ. Sci., 3 (2): 67-74, 2007

\section{RESULTS AND DISCUSSION}

Profile of the respondents: In the present study 1200 people were interviewed in Tehran, out of whom $33.39 \%$ lived in the north, $33.47 \%$ in the center and $33.14 \%$ in the southern part of Tehran. Out of them, $48.8 \%$ were female and $51.2 \%$ were male. In terms of age structure, about $19.1 \%$ of them were under 20 , $43.5 \%$ were in their $20 \mathrm{~s}, 20.4 \%$ in their $30 \mathrm{~s}, 9.7 \%$ in their $40 \mathrm{~s}, 5 \%$ in their $50 \mathrm{~s}, 1.9 \%$ in their $60 \mathrm{~s}$ and $0.3 \%$ in their 70s. Table 2 represents the profile of the respondents based on their level of education. About $23 \%$ of them had received secondary and high school certificate, $43.4 \%$ of them had diploma and $26.2 \%$ had received higher education certificates, including bachelor, MSc and Ph.D, while only $0.9 \%$ of them were illiterate.

Table 3 shows the status of respondent's occupation. As we will note later, occupation is one of the factors that influence respondent's environmental behavior and affects their environmental attitudes as well as their preparedness to act in the environment. According to this Table more than one-fifth of the respondents were house wives and $20.8 \%$ were student. About $18.3 \%$ of them were private employee and $15.7 \%$ engaged in public sector. Only $9.5 \%$ of the respondents were jobless.

Income is also a crucial factor in explaining environmental behavior. The income level of the respondents is shown in Table 4. As it is depicted from the Table, $43.7 \%$ of the respondents do not earn any income because they are jobless, house wives or student. About $15.1 \%$ of them had income level of less than 1000,000 Rls. Where as, only $2.3 \%$ had more than 4000,001 Rls. of monthly income.

Modeling of the data: To measure the sophisticated concepts, five Likert-type scales for evaluating environmental attitude, opinions about environmental legislation, preparedness to act, feeling of stress and environmental behavior containing 10, 4, 6, 7 and 10 items respectively, were used to measure these concepts. Thus by transforming the categorical responses into interval data, it was possible to use several parametric tests to examine hypotheses and elaborate the conceptual model.

One of the hypotheses of the present study was to examine significant difference between men and women attitudes towards environment. To test this hypothesis, student's t test was used. The results of this test are presented in Table 5.

Table 5 shows that, there is a significant difference between men and women attitudes regarding environmental legislation and their behavior towards environment. Most of the women believe that current environment legislation is sufficient for the protection of environment; whereas most of the male respondents emphasizes that more environmental laws have to be
Table 2: Respondents by education level

\begin{tabular}{lcc}
\hline Education & Frequency & Percent \\
\hline Illiterate & 11 & 0.9 \\
Functional & 24 & 2.0 \\
Primary school & 52 & 4.4 \\
Secondary school & 138 & 11.6 \\
High school & 136 & 11.4 \\
Diploma & 517 & 43.4 \\
Bachelor & 275 & 23.1 \\
MSc \& Ph.D & 37 & 3.1 \\
Religious education & 2 & 0.2 \\
Total & 1192 & 100 \\
\hline
\end{tabular}

Table 3: Respondents by occupation

\begin{tabular}{lcc}
\hline Occupation & Frequency & Percent \\
\hline House wives & 252 & 21.1 \\
Jobless & 113 & 9.5 \\
Industrial worker & 46 & 3.8 \\
Student & 248 & 20.8 \\
Public employee & 188 & 15.7 \\
Private employee & 219 & 18.3 \\
Specialist & 55 & 4.6 \\
Top manager & 8 & 0.7 \\
Other & 66 & 5.5 \\
Total & 1195 & 100 \\
\hline
\end{tabular}

Table 4: Respondents by income

\begin{tabular}{lcc}
\hline Monthly Income level (R1s.) & Frequency & Percent \\
\hline Without income & 516 & 43.7 \\
Less than or equal to 1000,000 & 178 & 15.1 \\
1000,001 - 2000,000 & 270 & 22.9 \\
2000,001 - 3000,000 & 143 & 12.1 \\
3000,001 - 4000,000 & 46 & 3.9 \\
4000,001 and more & 27 & 2.3 \\
Total & 1180 & 100 \\
\hline
\end{tabular}

Table 5: Independent student's t- test for examining difference between men and women attitudes towards environment

\begin{tabular}{lll}
\hline Items & t- value & Sig. level \\
\hline Environmental attitudes & 0.559 & 0.576 \\
Preparedness to act & 1.762 & 0.078 \\
Feeling of stress & 1.304 & 0.193 \\
Environmental legislation & 3.064 & $0.002 * *$ \\
Environmental behavior & 4.584 & $0.000^{* *}$ \\
\hline ** Significant at 0.01 level & &
\end{tabular}

** Significant at 0.01 level

passed by the government to protect the environment. For the other aspects, like environmental attitudes, preparedness to act and feeling of stress, there were no significant differences between men and women.

Another importance hypothesis was that to examine significant difference between the attitudes of the residents of north, center and south of Tehran towards environment. Same hypotheses were examined in the cases of education, occupation and income level. ANOVA along with Duncan test were used to examine these hypotheses (Table 6).

Table 7 depicts that there is significant difference between people residing in the north, center and south of Tehran in terms of preparedness to act, environmental legislation and feeling of stress. Environmental behavior is also significantly different between people with different occupation and income. Duncan's test shows that preparedness to act (with Duncan value of 24.41 and feeling of stress with 
Am. J. Environ. Sci., 3 (2): 67-74, 2007

Table 6: Analysis of variance for place of residence, education, occupation and income

\begin{tabular}{|c|c|c|c|c|c|c|c|c|}
\hline \multirow[t]{2}{*}{ Items } & \multicolumn{2}{|c|}{ Place of residence } & \multicolumn{2}{|l|}{ Education } & \multicolumn{2}{|c|}{ Occupation } & \multicolumn{2}{|l|}{ Income } \\
\hline & $\mathrm{F}$-Value & Sig. & $\mathrm{F}$-Value & Sig. & $\mathrm{F}$-Value & Sig. & F-Value & Sig. \\
\hline Environmental attitude & 1.46 & 0.233 & 1.89 & $0.05^{*}$ & 3.51 & $0.001 * *$ & 1.86 & $0.05^{*}$ \\
\hline Preparedness to act & 7.04 & $0.001 * *$ & 1.09 & 0.36 & 1.43 & 0.18 & 0.42 & 0.84 \\
\hline Environmental legislation & 5.47 & $0.004 * *$ & 1.35 & 0.21 & 2.89 & $0.003^{* *}$ & 0.22 & 0.95 \\
\hline Feeling of stress & 16.42 & $0.000 * *$ & 2.32 & $0.01 * *$ & 2.05 & $0.04 *$ & 0.96 & 0.44 \\
\hline Environmental behavior & 0.64 & 0.527 & 1.71 & 0.08 & 3.62 & $0.00 * *$ & 8.59 & $0.00 * *$ \\
\hline
\end{tabular}

Table 7: Correlation among different variables

\begin{tabular}{llll}
\hline Variables & $\begin{array}{l}\text { Correlation } \\
\text { type }\end{array}$ & $\begin{array}{l}\text { Environmental } \\
\text { Attitude }\end{array}$ & $\begin{array}{l}\text { Environmental } \\
\text { behavior }\end{array}$ \\
\hline Environmental legislation & Pearson & $0.353^{* *}$ & $0.081^{* *}$ \\
Feeling of stress & Pearson & $0.120^{* *}$ & 0.014 \\
Preparedness to act & Pearson & $0.291^{* *}$ & $0.123^{* *}$ \\
Age & Pearson & 0.043 & 0.003 \\
Education & Spearman & $0.079^{* *}$ & 0.026 \\
income & Spearman & -0.033 & $0.179^{* *}$
\end{tabular}

** Correlation is significant at 0.01 level

Table 8: Direct and indirect impacts of the independent variables

\begin{tabular}{llll}
\multicolumn{2}{c}{ on Environmental behavior } & & \\
\hline Variables & $\begin{array}{l}\text { Direct } \\
\text { impact } \\
\text { impacts }\end{array}$ & $\begin{array}{l}\text { Indirect } \\
\text { Impacts }\end{array}$ & Total \\
\hline Education & - & 0.055 & 0.055 \\
Age & 0.07 & 0.006 & 0.076 \\
Income & 0.20 & - & 0.200 \\
Environmental legislation & - & 0.022 & 0.022 \\
Environmental attitudes & 0.09 & 0.021 & 0.111 \\
Feeling of stress & - & 0.044 & 0.044 \\
Problem-based knowledge & - & 0.011 & 0.011 \\
Preparedness to act & 0.11 & - & 0.110 \\
\hline
\end{tabular}

Duncan value of 30.07) in the north of Tehran is much higher than the center (with Duncan value of 23.64 in respect of preparedness to act and 23.34 regarding feeling of stress) and south (with Duncan value of 23.64 and 23.48) respectively. But there is no difference between people residing in the center and south of Tehran in respect of preparedness to act and feeling of stress.

To analyze the relationship between the variables, correlation analysis was applied. Table 7 clearly demonstrates that there was a significant correlation between environmental attitude with environmental legislation, feeling of stress, preparedness to act and education, while environmental behavior had significant correlation with environmental legislation, preparedness to act and income.

Path analysis: A model for environmental attitudes and behavior, (Fig. 1), was used as a cause/effect chain to work out path analysis. As the qualitative variables of this model were measured through various items in the form of Likert type scale; thus by adding up these items, a quantitative set of data for each of the variables was obtained and the path analysis was calculated. The cause/effect coefficients of the variables derived from the various steps of the regression calculation. Figure 1 depicts all the path coefficients obtained from multiple
Table 9: Direct and indirect impacts of the independent variables on environmental attitudes

\begin{tabular}{llll}
\hline Variables & $\begin{array}{l}\text { Direct } \\
\text { Impact }\end{array}$ & $\begin{array}{l}\text { Indirect } \\
\text { impact }\end{array}$ & $\begin{array}{l}\text { Total } \\
\text { impact }\end{array}$ \\
\hline Education & 0.09 & 0.013 & 0.103 \\
Feeling of stress & 0.12 & - & 0.12 \\
Problem-based knowledge & - & 0.013 & 0.013 \\
\hline
\end{tabular}

Table 10: $\quad$ Direct and indirect impacts of the independent variables on preparedness to act towards environmental protection

\begin{tabular}{llll}
\hline Variables & $\begin{array}{l}\text { Direct } \\
\text { Impact }\end{array}$ & $\begin{array}{l}\text { Indirect } \\
\text { impact }\end{array}$ & $\begin{array}{l}\text { Total } \\
\text { impact }\end{array}$ \\
\hline Education & 0.06 & 0.062 & 0.122 \\
Environmental legislation & 0.20 & - & 0.200 \\
Environmental attitudes & 0.19 & - & 0.19 \\
Feeling of stress & 0.25 & 0.023 & 0.273 \\
Problem-based knowledge & 0.08 & 0.031 & 0.111 \\
\hline
\end{tabular}

Table 11: Direct and indirect impacts of the independent variables on feeling of stress environmental problems

\begin{tabular}{llll}
\hline Variables & $\begin{array}{l}\text { Direct } \\
\text { Impact }\end{array}$ & $\begin{array}{l}\text { Indirect } \\
\text { impact }\end{array}$ & $\begin{array}{l}\text { Total } \\
\text { impact }\end{array}$ \\
\hline Education & 0.09 & 0.02 & 0.110 \\
Age & 0.10 & 0.015 & 0.115 \\
Problem-based knowledge & 0.11 & - & 0.11 \\
\hline
\end{tabular}

regressions. The path coefficients show that the direct effects of some variables on the others were not significant at the 0.05 level. Thus, in the final model these paths were discarded. Figure 2 shows the most acceptable model derived from the data obtained i.e. the most efficient representation of the cause/effect structure. All the significant path coefficients at 0.05 levels were indicated in the model. This model was finalized in a two-stage process. In the first stage the model was appropriately adjusted, in the second stage all statistically non-significant and non-relevant paths were eliminated. The direct effect of one variable on another can be seen from the weighting given by the path coefficient; its value lies in the range between - 1 to +1 and indicates the relative change in the dependent variable for any change in the independent variable. Any additional, indirect influences were determined by multiplying the path coefficients of indirect paths. The direct and indirect effects of each independent variable on the dependent variable of environmental behavior were calculated as indicated in Table 8.

An important hypothesis in the discourse on environmental attitude and behavior was that concern about the environment increase with the level of formal education. This hypothesis was not confirmed by the 


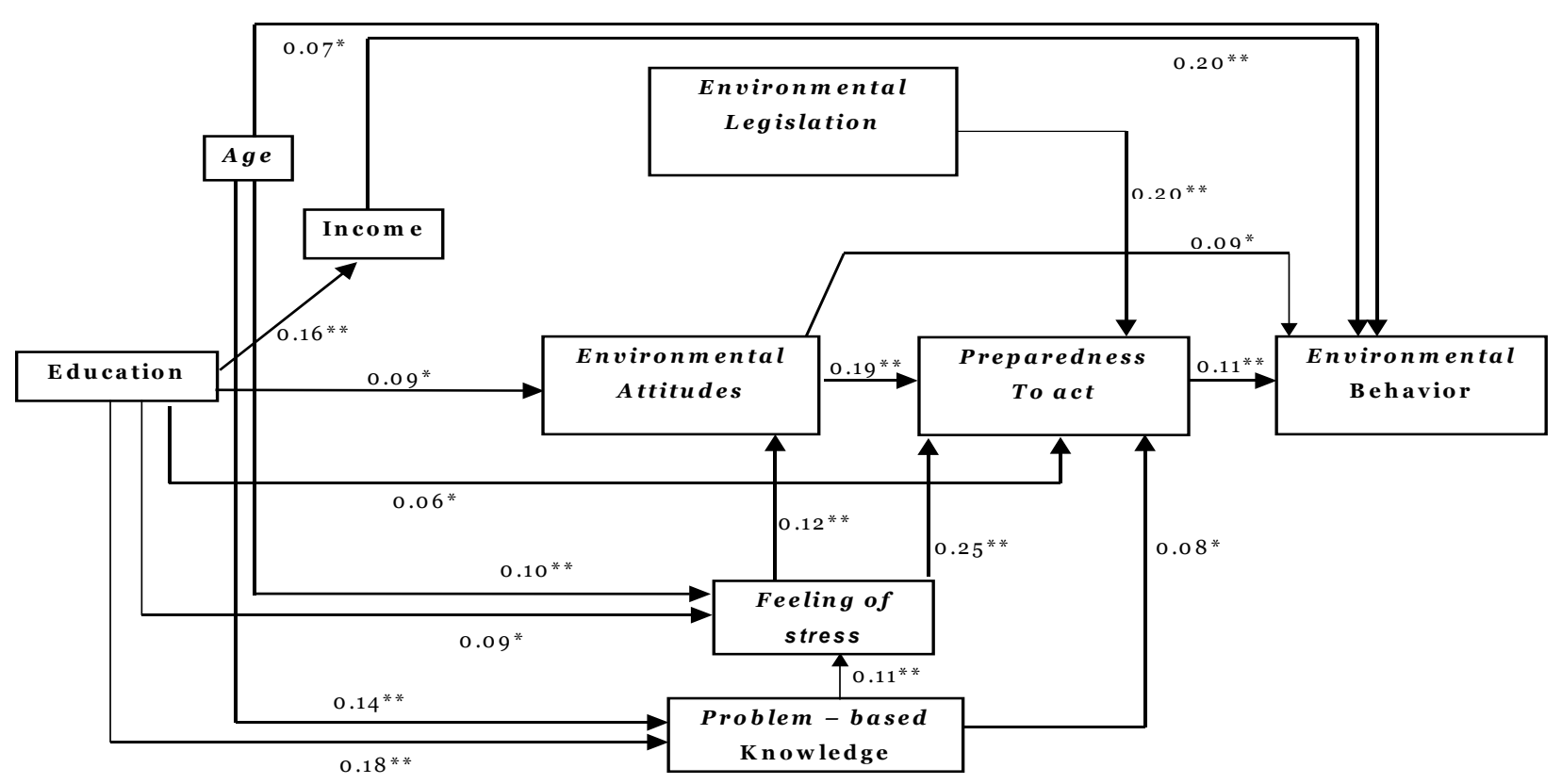

Fig. 2: Path diagram of the final model. The path coefficients are linear and standardized. The significance is: * $0.05 \geq \mathrm{p}>0.01$ and $* * 0.01 \geq \mathrm{p}>0.001$. The non-significant paths were discarded. Data source: Responses from 1200 Tehran residents

study in respect of the environmental behavior, though it influenced environmental behavior indirectly through the "environmental attitude", "feeling of stress", "problem-based knowledge" and preparedness to act (Fig. 1). Furthermore, "problem-based knowledge" also did not have a direct influence on environmental behavior, but it also acts through "feeling of stress" and "preparedness to act".

Initial assumptions were also made regarding certain other significant exogenous variables, namely age, gender and income. It was assumed that age and gender would affect all attitudinal components (feeling of stress, problem-based knowledge and preparedness to act) as well as environmental behavior. Indeed, it was explicitly postulated in respect of age that the elder respondents would exhibit a more environmentally conscious attitude than their youngest. This was confirmed for environmental behavior at $0.05 \%$ level and for problem-based knowledge and feeling of stress at $0.01 \%$ probability level. Furthermore, significant difference was confirmed on the basis of gender in respect of environmental attitude, feeling of stress, preparedness to act and environmental behavior. In respect of income, it was assumed that, it would influence environmental attitude, preparedness to act and environmental behavior. However the first two variables did not appear to be influenced by income, but it would affect the environmental behavior, significantly. However, problem-based knowledge did not influence environmental attitudes and environmental behavior, significantly, but it affects both the variables through feeling of stress and preparedness to act. It was itself influenced by age and level of education. "Environmental attitude" as a main variable influenced two important components of "preparedness to act" and "environmental behavior". Whereas, this factor itself was affected by the variables of "education" and "feeling of stress" with path coefficient of 0.09 and 0.12 , respectively. This sense of environmental stress leads directly to greater interest in preparedness to act for friendly environmental behavior.

In the model, environmental behavior was the variable at the end of the cause/effect chain, the one to be explained. Within the framework of the original model (Fig. 1), a causal connection was postulated between the components of attitude and behavior. Furthermore, each endogenous variable of the concept was also supposed to have an effect on environmental behavior.

The empirical results deriving from the data show that there are certain strong influences of the attitudinal components on behavior, those represented by the two high - value path coefficients emanating from, 


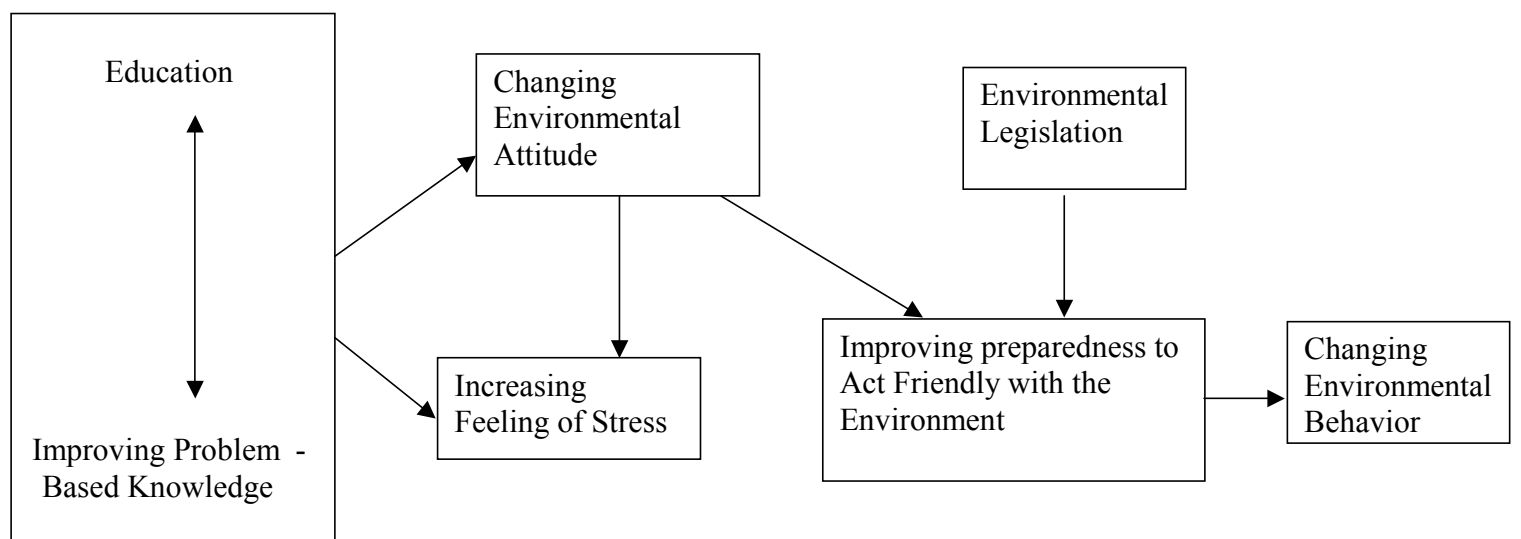

Fig. 3: Conclusion framework

"preparedness to act" and "environmental attitude". There was, however, no direct influence on environmental behavior of three components of the initial model, namely "feeling of stress", "environmental legislation" and "problem-based knowledge". However, age and income were the only exogenous variables, which directly affected the environmental behavior. Direct and indirect impacts of independent variables on environmental behavior are presented in Table 8. It shows that income has the highest direct impact on the environmental behavior $(0.20)$. Environmental attitude and preparedness to act with total impact value of 0.111 and 0.110 stand in the second and the third positions, respectively.

Table 9 clearly indicates that environmental attitude is highly influenced by two important variables of feeling of stress (0.12) and education (0.103). While problem-based knowledge (0.013) is next to these factors. Table 10 on the other hand, shows that preparedness to act is under the influence of five factors of feeling of stress (0.273), environmental legislation $(0.20)$, environmental attitude $(0.19)$, education $(0.122)$ and problem-based knowledge (0.111).

It is also depicted from Table 11 that age (0.115), education (0.110) and problem-based knowledge (0.11) influence feeling of stress in the society. It seems that by improving problem-based knowledge of people and providing education, feeling of stress towards environment goes up which in turn it strongly affects preparedness of people to tack care of environment and change the environmental behavior.

\section{CONCLUSION}

The findings of the present study showed that there was no significant difference between men and women in terms of environmental attitudes, preparedness to act and feeling of stress. But the opinions of women and men were different in respect of environmental legislation. However women emphasized that current environmental legislations are sufficient for environmental protection; and if the laws were completely enforced, environmental problems could be solved. But most of the men believed that these legislations were not adequate and government should pass more laws to make ordinary people and business to protect the environment. The study also showed that there was significant difference between men and women in respect of environmental behavior. Women were generally more concerned than men. This conclusion is also confirmed by Caiazza and Barrett ${ }^{[6]}$.

Feeling of stress among people in the north of Tehran is higher than the center and south. Due to this feeling; preparedness to act for environmental conservation among people of the north of Tehran is also high. This conclusion is also true in the case of specialists and top managers as compared with the employees.

Deriving from the data set, the model presented in Fig. 2 demonstrates the direct and indirect cause/effect relationships among environmental attitude and behavior with some basic variables such as income, age, education, problem-based knowledge, feeling of stress and preparedness to act. The strongest direct paths to environmental behavior stem from income $(0.20)$, preparedness to act $(0.11)$ and environmental attitude (0.09). Feeling of stress (0.25), environmental legislation (0.20) and environmental attitude (0.19) also influence environmental behavior through preparedness to act. An effect of age was confirmed by the path coefficient of 0.07 . These relationships were proved by a number of studies worked out by; Hines et al. ${ }^{[18]}$, 


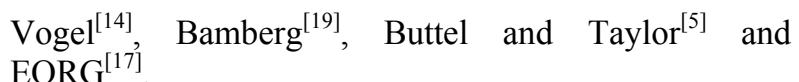

Education and problem-based knowledge had indirect impact on environmental behavior. However the direct influence of education on environmental attitude was also confirmed. There were several studies suggesting that education plays an important role in enhancing the environmental attitude and behavior relationship by providing individuals with the ability to better formulate alternate views and present arguments to support their believes and behaviors ${ }^{[17]}$. It is emerged from the present study that education and improving problem-based knowledge of Tehran residents can change environmental attitude and increase feeling of stress of people towards environment. These changes in turn improve preparedness to act friendly with the environment, particularly with the help of environmental legislation. All these can change behavior to preserve environment. This conclusion is presented in Fig. 3.

\section{ACKNOWLEDGEMENTS}

The study was based on a research project financially supported by the World Bank and the Department of Environment of Iran, which is highly appreciated.

\section{REFERENCES}

1. Dunlap, R.E. et al., 1998. The new environmental paradigm. J. Environ. Edu., 9: 19-40.

2. Albrechet, D. et al., 1992. Measuring environmental concern: The new environmental paradigm scale. J. Environ. Edu., 13: 39-43.

3. Cluck, R. et al., 1997. Attitudes towards and commitment to environmentalism: A multidimensional conceptualization. Paper presented at the 60th Meeting of the Rural Sociological Society, Toronto, Ontario, Canada.

5. Buttel, F. and P. Taylor, 1999. Environmental sociology and global environmental change: A critical assessment. Ed: M. Redclift and T. Bemtpm/ Social Theory and the Global Environment. Routledge, London.

6. Caiazza, A. and A. Barrett, 2003. Engaging women in environmental activism: recommendations for Rachel's network. Institute for Women's Policy Research. IWPR Publication, Washington, Dc.

4. Tuna, M., 1994. Environmentalism: An empirical test of multi-effect on environmental attitudes in more and less developed countries. Unpublished Dissertation, Mississippi State University, USA.

7. Stern, P. et al., 1998. Value orientations, gender and environmental concern. Environ. Behav., 25: 322-348.

8. Tarrant, M. and K. Cordell, 1997. The effects of respondent characteristics on environmental attitude-behavior correspondence. The J. Environ. Edu., 29: 618-637.

9. Arcury, T.A., 2000. Environmental attitude and environmental knowledge. Human Organ., 49: 300-4.

10. Tommy, G. et al., 2002. Moderating effects of social value orientation on determinants of proenvironmental behavior intention.

11. McFarlanc, B. and P. Boxall, 2003. The role of social psychological and social structural variables in environmental activism: An example of the forest sector. J. Environ. Psychol., pp: 79-87.

12. Schultz, P.W. and L.C. Zelezny, 1999. Value as predictors of environmental attitudes: Evidence for consistency across cultures. J. Environ. Psychol., 19: 255-265.

13. Mohai, P. et al., 1987. Age and environmentalism: An elaboration of the Buttel model using national survey evidence. Social Sciences Quarterly.

14. Vogel, S., 1994. Environmental attitudes and behavior in the agricultural sector as empirically determined by use of an attitude model. Institut Fur Wirtschaft, Politik and Recht, Univrsitat, Bodenkutur Wien.

15. Arcury, T.A. and T.P. Johnson, 1995. Public environmental knowledge: A statewide survey. J. Environ. Edu., 18: 31-37.

16. Cottrell, S.P. and A.R. Graefe, 2002. Testing a conceptual framework of responsible environmental behavior. The J. Environ. Edu., 29: 17-27.

17. The European Opinion Research Group (EORG), 2002. The attitudes of Europeans towards the environment. The European Opinion Research Group.

18. Hines, J.M. et al., 1987. An analysis and synthesis of research on responsible environmental behavior: The J. Environ. Edu., 18: 1-8.

19. Bamberg, S., 2003. How does environmental concern influence specific environmentally related behaviors? A new answer to an old question. J. Environ. Psychol., 23: 21-23. 